often distressing, especially in the case of adults. Though no fatal results have been recorded the occurrence of such accidents invites us to adopt a safer and pleasanter method of treatment. M. Comby states that it is only exceptionally that serum phenomena of any importance bave to be deplored, but it must be remembered that the cases recorded are relatively few and there is always the possibility of the occurrence of such sequela. On reference to Mourniac's thesis it will be found that in five out of the 18 cases these serum phenomena were noted.

I am, Sirs, yours faithfully,

Grove Hospital, S.W., July 28th, $1906 . \quad$ J. D. RoLLESTON.

\section{THE ELECTRO-CONDUCTIVITY OF BODY FLUIDS.}

To the Editors of THE LANCuT.

SIRS,-Dr. Dawson F. D. Turner's remarks on the electrical resistance of the blood and urine in THE L A NCET of July 28th, p. 223, are of great interest, and the hope which he expresses that this method of research may come into extended use in the future deserves emphasis. There seems little doubt that electro conductivity measurements of body fluids may throw considerable light on their nature. $I$ also think that in practice cryoscopy may also be supplanted by electro-conductivity measurement, even though the two methods depend on different things. As regards the determination of the functional efficiency of the kidney by this method I believe that the use of the "salt" and "water" tests introduced by Strauss is almost certain. The tests consist in this - that a single large dose of salt or water is given after a night's fast; the urine collected bourly and examined. In this case I find that the conductivity follows the same curve that the freezing-point depression has. The former may therefore do in place of a cryosopic determination.

It seems to me, however, that one or two points must not be lost sight of. One is that the electrical method does not give a reliable figure for the concentration of the electrolytes, whereas cryoscopy gives a definite figure for the total concentration. It is true that by combining with the conductipity-determination an estimation of the chlorides (Volhardt's method) one can deduce the concentration of the achloride electrolytes (in terms of $\mathrm{NaCl}$ ) which does vary under different conditions. But it is not as satisfactory a deduction as can be desired. The second point is that the presence of colloids greatly influences the conductivity. Tangl and Bugarsky found that every gramme of albumin diminishes the conductivity of blood serum by 2.5 per cent. ; not only this, but the albumin also diminishes the degree of dissociation of the serum electrolytes. It is for this reason that I think the electrical method fails in the case of the examination of the blood.

The last point is one of considerable importance. The expression of results as "specific resistance" in ohms is simple but has the great objection that the number only holds good when the electrodes and vessels used are of certain dimensions (which Dr. Turner gives). If one determines the capacity of the vessel and expresses the results as equivalent conductivity the size of electrodes and vessel, \&s., ceases to matter. The figures obtained by any observer will then agree with those of any other. The minute electrodes described do not give as accurate results as large ones, which could well be employed if one were to use venesection blood. The electrical method has, in my experience without exception up to now, shown a difference between various kinds of body fluids such that it would be possib'e by this simple method alone to diagnose the source of a given fluid. I am, Sirs, yours faithfully,

Clinical Laboratory, Leeds General Infirmary,

$$
\text { OSKAR C. GRUNER. }
$$

July 28 th, 1906

\section{WHAT IS A SPECIALIST?}

\section{To the Editors of THE LANCET.}

SIRs,-Are the re not several ways in which "A. Z." could advertise bis desire for special work without being "infamous." He might put a notice in bis waiting-rosm that in future he will only see certain cases. He might send a circular letter to his regular patients. He might send a circular note to the other general practitioners in his district intimating that he was giving up general practice to take op a specialty and asking for their support. If he has any claim to special knowledge this Jast method would, no doubt, be successful.

Isondon, July 28th, 1906.

J. W.

\section{THE CHICAGO MEAT SCANDAL.}

\section{HOW THE POPULAR PRESS MAY PREVENT REFORM,}

\section{(By our SPecial Sanitary Commissioner.)}

THERE can be no doubt that the public is thoroughly roused on the general question of food-supply and on the special grievance in rf gard to the Chicago stockyards. On all sides, among all classes of the community, conversations constantly turn to these questions. This widespread interest may, if properly directed, produce very beneficent results, but there is great danger that the present indignation will wear itself out without acbieving anything of a very durable and efficacious character. For many jears efforts have been made to obtain better laws and more $t$ ffective control over cattle and meat markets, slaughter-houses, and food-preserving establishments. The denunciations which inspectors have made annually of the insanitary condition of jam and other factories where animal or vegetable substances are preserved for food have past unnoticed by the general putlic. This year, however, these repurts of the Government and municipal inspectors have been carefully scanned and the most sensational passages have been widely reproduced by the press at large. All this is excellent: it educates the public as to existing evils and prepares the way for future legislation. So long as the lay press contents itself with reproducing the reports of qualified official inspectors and of technicians nothing but good will result. Unfortunately the very popularity which the subject now enjoys has led a number of persons to rush into print though they know absolutely nothing about the technicalities at issue. As the general public is equally ignorant, it is not capable of distinguishing between those who write with technical knowledge and those who are unacquainted with what constitutes a properly constructed abattoir or effective meat inspection.

In the United States of America this is not the first time that the abominations prevalent at Chicago have been denounced. A ter the Spanish-American war there was a great "embalmed meat" scare and the Senate had to appoint a court of inquiry which issued a report of about 3000 pages. Here all the abominations of the Chicago stockyards were attack ed hip and thigh. But the whole thing died down, though it was commonly believed, and said, that the American troops in Cuba had suffered more from the canned meat which they received from Chicago than from the bullets fired at them by the Spaniards. The fact that even in such circumstances the agitation could possibly nave died down should be considered as a very grave warning. Care must be taken that the present outcry is not stifled in a similar manner. To effect this end the Chicago packers and other interesten parties will encourage the present tendency to introduce non-technicians into the controversy. Appeals will be made to the daily political press to send their reporters and correspondents to view premises and to write reports thereon. These correspondents, though many of the $m$ very able men and admirable writers, have naturally no idea as to the nature of the defects which they should seek out. They will be impressed by an outward appearance of cleanliness and the tidy, perhaps coquettisb, aspect of the young women employed to dress some of the meat and to fill some of the cans. As a result, there will be whitewashing accounts published of the Chicago stockyards and also of some British establishments, and thus it is hoped to lull the public once more into a sens of false security.

As a proof and demonstration of this very imminent and serious danger nothing could be more to the point than an article published in the London Daily Chroniole of July 27th last. First, there are three delightful cartoons by Mr. Tom Browne and then a paragraph giving a complimentary notice of the princely terms offered by the Chicago Daily Tribune to this British artist to draw for that paper. So far so good, 